\title{
CORRESPONDENCE.
}

\section{INTRA-CAPSULAR EXTRACTION OF CATARACT}

To the Editor, The British Journal of Ophthalmology. SIR,

As the Ophthalmic Review has ceased to exist, having become merged in THE BRITISH JOURNAL OF OPHTHALMOLOGY, I would ask the favour of a little of your space to reply to Colonel Fisher's remarks on "Intra-capsular Extraction of Cataract" in the last number of the former journal, as he has referred to my work therein. The term "complete operation" is objectionable as being a slur upon extraction; "expression" is definite and precise, and indicates one of the main features of the operation-viz.: the squeezing out of the lens. I used this term in my "Manual of Ophthalmic Operations," published in 1908, and it has been adopted by Continental surgeons. As regards Colonel Fisher's saying, that we condemned Smith's operation before seeing it, [ would say that I saw Smith do it several times, and operated upon some cases under his direction a year before publishing a qualified approval of it in the book above referred to. Latterly, I have almost ceased to do the operation; partly because of the frequency of complications, prolapse of vitreous and iris (quite the most troublesome of all, as Colonel Fisher and American writers will agree) and ruptured capsules, and partly because of poorer average visual results after it. In 1,325 cataract operations performed by me in hospital practice in 1916, only 26 were expressions in the capsule. I do not share Colonel Fisher's hopeful views of the future of expression, though I am far from minimising the drawbacks of cortex troubles. If increase in operations in a place forms an argument in favour of an operation, I might quote my own increase here from 478 to 1,325 annually (in spite of woeful lack of accommodation) as an argument in favour of extraction, but so many factors are concerned in the increase that I do not think it a very certain indication, though it is valuable, ceteris paribus, no doubt. I agree that expression does not abolish suppuration, as claimed by its advocates; and, personally, I have not succeeded in reducing suppuration below one per cent., though one may have a run of over 100 operations without one. Preliminary bacteriological examinations of the conjunctival sac in all cases (with treatment of infected conjunctivæ) have been introduced into one of the hospitals under my control for over a year now. The results have been disappointing, and the incidence of sepsis has not been abolished or even reduced as much as was hoped, so 
difficult is the sterilisation of the conjunctival sac and the adjacent passages. Yours, etc.

Calcutta,

4th February, 1917.

\author{
F. P. MAYNARD, Lieut.-Col. I.M.S.
} Professor of Ophthalmic Surgery. Medical College.

\title{
BOOK NOTICES.
}

Transactions of the Ophthalmological Society of the United Kingdom. Vol. XXXVI. Session 1916. London: J. \& A. Churchill, 7, Great Marlborough Street. I9I6.

The present volume of the Transactions includes the proceedings of the Ophthalmological Society of the United Kingdom during its thirty-sixth session, April, 1916. Although it bears the date 1916, it did not come into the hands of members until recently. As usual, it forms a substantial book, well illustrated with plates and diagrams. Such of its contents as are suitable will be abstracted in due course in these columns. Among other contents we may note that it contains accounts of two important discussions:-1. On the treatment of syphilitic eye affections by the newer methods ; 2 . On foreign bodies in the eye and orbit, with special reference to prognosis and treatment; not to mention the interesting Report of the Committee on Detachment of the Retina, appointed at the 1915 Congress.

\section{S. S.}

Exophthalmos, its causes and diagnosis. By R. BEATsOn HiRD.

The Richard Middlemore Post-Graduate lecture for I9I6.

Birminghain Medical Review, Nov.-Dec., r916.

In this lecture, Beatson Hird has confined himself to the ætiology and differential diagnosis of protrusion of the orbital contents.

The first three pages contain a brief account of the surgical anatomy of the region of the orbit.

The author next classifies the various causes of protrusion of the orbital contents, the majority of cases being due to some encroachment on the orbital cavity as a result either of deformity of the orbital walls or increase of the orbital contents.

The list given is a very complete one. Our own experience, however, fails to confirm the author's statement that hydatid cysts frequently develop in one of the ocular muscles.

A second group of cases is mentioned as due to diminished retraction following paralysis of the oculomotor nerves and tenotomies of the ocular muscles. Finally, there is a third group due to "protraction" of the globe, such as is found in Bright's disease. In this condition Hird considers that the "protraction" is probably due to a circulating toxin acting as a sympathetic stimulant, as may also be the case in Graves' disease. 